\title{
Pecios españoles en aguas colombianas: conjugación entre el patrimonio cultural subacuático y la inmunidad jurisdiccional de los Estados
}

\author{
Andrea Mateus-Rugeles* \\ Ingrid Rodríguez Valenzuela**
}

\begin{abstract}
RESUMEN
Las Mercedes, La Galga, Juno, y San José, son solo algunos de los pecios que han permanecido por siglos sumergidos; su naturaleza jurídica y la determinación de su propiedad son objeto de repetidos conflictos. Uno de esos conflictos se presenta cuando dos Estados reclaman como suyos los mismos bienes que constituyen patrimonio cultural subacuático (PCS). En este artículo se analizan las posibilidades que tienen los Estados colombiano y español, a partir de las legislaciones internas y disposiciones internacionales, para proteger bienes que son considerados por ambos como parte de su PCS. Igualmente se analiza el rol que tiene la figura de la inmunidad de jurisdicción de los Estados, en dichas posibilidades.
\end{abstract}

Patrimonio Cultural Subacuático - inmunidad de jurisdicción de los Estados Colombia y España

\section{Spanish shipwrecks in colombian waters: conjugation between underwater cultural beritage and jurisdictional immunities of states}

\begin{abstract}
Las Mercedes, La Galga, Juno, y San José, are only a few of many shipwrecks that had been sunken for centuries; their legal characterization and the determination of their ownership are object of repeated legal battles. One of those battles appears when two states claim the ownership over the same objects that constitute underwater cultural heritage (UCH). This article analysis the possibilities that the Colombian and the Spanish states have before the national and international laws, in order to protect objects that are considered by both states as part of their own UCH. Likewise, the role that the jurisdictional immunities of states play in those possibilities is analyzed.
\end{abstract}

Underwater Cultural Heritage - jurisdictional immunities of states Colombia and Spain

* Master en Derecho Internacional de la Universidad de Nueva York. Docente principal de la carrera de Derecho Internacional de la Facultad de Jurisprudencia de la Universidad del Rosario. Este artículo hace parte de la línea de investigación de Derecho Internacional y Globalización del Grupo de investigación de Derecho Internacional de la Universidad del Rosario. Correo electrónico: andrea.mateus@urosario.edu.co. 


\section{INTRODUCCIÓN}

U n reciente estudio (encaminado a la protección del Patrimonio Cultural Subacuático) realizado por la Armada española concluyó que hay más de 1.500 buques españoles hundidos en diferentes lugares de los océanos. El 26,7\% de estos pecios se encuentran en América del Norte, América Central y el Caribe, y el $64,1 \%$ se hundieron entre los siglos XVI a XIX ${ }^{1}$. Teniendo en cuenta el marco temporal abarcado por el estudio, se puede afirmar que por lo menos algunos de esos pecios corresponden a embarcaciones de la época de la Colonia española, con cargamentos que pueden constituir patrimonio cultural subacuático (PCS).

Por ejemplo, en 1982 se descubrió el galeón español, San José, hundido en el caribe colombiano. Para efectos de determinar la propiedad del cargamento, así como la naturaleza jurídica de los bienes, los salvadores acudieron a distintas instancias judiciales colombianas y estadounidenses. La Corte Suprema de Justicia de Colombia en casación, afirmó que algunos de los bienes encontrados en dicha embarcación podían constituir “especies náufragas” y otros "tesoros”. La legislación colombiana aplicable para efectos de determinar estas cuestiones ha ido variando a lo largo de los años, siendo la Ley 1675 de 2013 y su Decreto 1698 de 2014 la normatividad vigente.

Otro caso que soporta los resultados del referido estudio, esta vez en aguas internacionales, es el caso de Las Mercedes. En el 2007 la empresa de salvamento Odyssey Marine Exploration anunció que había encontrado un pecio, e inició un proceso ante los tribunales de Estados Unidos para solicitar la propiedad acerca de su hallazgo. Frente a este hecho, España reclamó su titularidad respecto del buque para obtener la devolución de los bienes encontrados. El resultado fue su victoria jurídica, pues al probar que se trataba del barco Nuestra Señora de las Mercedes (Las Mercedes), un buque de la Armada española, se debía aplicar la ley de Estados Unidos sobre inmunidades de la soberanía extranjera (FSIA), y por tanto los tribunales estadounidenses no tenían jurisdicción para conocer del caso $^{2}$.

Ambos casos ilustran conflictos que empiezan a darse con mayor frecuencia en diferentes tribunales de Estados de todo el mundo, debido a los últimos avances tecnológicos que permiten la recuperación de pecios; el creciente interés en el PCS y su protección; así como la internacionalización de las disputas que se dan con ocasión de su recuperación. En casos como estos, surgen diversos cuestionamientos jurídicos relativos a la aplicación de regulaciones que confluyen para una misma situación. Uno de dichos cuestionamientos, y que se presenta como denominador común en los dos casos, es la vía

${ }^{1}$ Armada Española, informe de prensa de 31 de enero de 2013. Tomado de: http://www.armada.mde. es/ArmadaPortal/page/Portal/ArmadaEspannola/ciencia_museo/prefLang_es/01_informacion-museo-naval--02_ prensa-museo-naval--01_noticias--2013--01--NT-014-Informe-naufragios_es?_selectedNodeID=1116007\&_ pageAction =selectItem.

${ }^{2}$ Florida Middle District Court, Odyssey Marine Exploration, Inc. vs. The unidentified shipwrecked vessel, its apparel, tackle, appurtenances and cargo located within center point coordinates, in rem, Kingdom of Spain, et al. 
jurídica por la que un Estado puede reclamar o acceder a su $\mathrm{PCS}^{3}$ que se encuentra en el territorio de otro Estado. Más interesante aún, es el caso en el que dos Estados reclaman como propios los bienes que pueden constituir PCS. ¿Existe una vía jurídica para que un Estado pueda reclamar su alegado patrimonio cultural que se encuentra sumergido en el territorio de otro Estado que también lo reclama como propio?

Con el fin de ilustrar el problema planteado, así como resolver el cuestionamiento, partiremos en este artículo de un caso hipotético -aunque no tan lejano a la realidad-, en el que existe una embarcación (no buque de guerra) española que fue hundida en mar territorial colombiano en el siglo XVII, y cuyo cargamento estaba compuesto, entre otros, de lingotes de oro, monedas de plata, piedras preciosas, extraídas de sus colonias.

$\mathrm{Al}$ respecto, es nuestra posición que tratándose de bienes que pueden ser considerados como PCS colombiano, de acuerdo con su legislación interna, y que a su vez son reclamados por España como de su propiedad, la ley colombiana sobre PCS permite que España recupere parte de tales bienes, reconociendo de manera implícita en unos casos, y explícita en otros, la existencia de un PCS compartido. El cuestionamiento se resuelve a partir de la contrastación entre las normas concernientes a inmunidades jurisdiccionales de los Estados, y aquellas sobre PCS.

Para esto, en el primer capítulo se hará una descripción de las fuentes que existen en materia de PCS e inmunidades jurisdiccionales de los Estados, tanto a nivel internacional como nacional, entendiendo por esta última dimensión las legislaciones de interés, esto es la colombiana y la española. En el segundo capítulo se estudiarán las fuentes y legislación aplicable al caso supuesto. En el tercer capítulo, se presentará tanto el cuestionamiento jurídico referido como la respuesta que sustenta nuestro argumento, para pasar finalmente a revisar, a partir del caso planteado, las consecuencias prácticas de su aplicación.

\section{Patrimonio cultural subacuático e inmunidad JURisdiccional: FUENTES INTERNACIONALES Y NACIONALES, CASO COLOMBIA Y ESPAÑA}

\section{Patrimonio cultural subacuático}

A nivel internacional, el patrimonio cultural ha sido regulado desde diferentes perspectivas. De manera general, la "Convención sobre la Protección del Patrimonio Mundial, Cultural y Natural” regula desde 1972 este tema, y define el patrimonio cultural

3 En relación con el concepto de patrimonio cultural "sumergido", "submarino" y "subacuático", cada uno tiene un alcance diferente. El primero se refiere al patrimonio que se encuentra bajo la superficie terrestre o bajo las aguas. El segundo indica el patrimonio situado bajo las aguas del mar, excluyendo otro tipo de aguas. El tercero, alude al patrimonio situado bajo toda clase de aguas. (Ruíz, R., El régimen jurídico del patrimonio cultural subacuático, Ministerio de Defensa, http://publicacionesoficiales.boe.es/, 2013, pp. 138, 139, 141 y 564). A pesar de esto, las legislaciones colombiana y española usan indistintamente estos términos. En este artículo se hará alusión en general a "patrimonio cultural subacuático" o "PCS", siguiendo el término acogido por la Convención sobre la Protección del Patrimonio Cultural Subacuático, y aplicándolo indistintamente a amabas legislaciones. 
a partir de tres categorías, los monumentos, los conjuntos y los lugares ${ }^{4}$. Con el fin de promover la protección de este patrimonio, en 1972 entra en vigor la Convención de Paris sobre las "Medidas que deben Adoptarse para Prohibir e Impedir la Importación, la Exportación y la Transferencia de Propiedad Ilícitas de Bienes Culturales" ${ }^{\circ}$ de 1970. Finalmente, se ha buscado también la protección de este patrimonio en el sentido de salvaguardia y respeto de los bienes culturales, en escenarios de conflicto armado a partir de la Convención de La Haya de $1954^{6}$.

Ya en 1982, con la "Convención de las Naciones Unidas sobre el Derecho del Mar", se empieza a regular de manera específica el PCS. Esta Convención que trata acerca del derecho del mar en general, trae dos disposiciones referidas a este tipo de patrimonio. El artículo 149 que en relación con los "objetos arqueológicos e históricos" que se encuentren en la "zona", indica que estos serán conservados o dispuestos en "beneficio de toda la humanidad", teniendo en cuenta el derecho de preferencia de los Estados que tengan un vínculo de origen cultural, histórico o arqueológico. A su vez, el artículo 303 también refiere la protección de los objetos arqueológicos e históricos hallados en el mar, a partir de medidas que puede establecer el Estado ribereño contra el tráfico de estos objetos. Sin embargo, y conforme a los numerales 3 y 4 de este artículo, todas estas disposiciones quedan sujetas a los derechos de los propietarios que sean identificables, a las normas respecto de salvamento o, en general, las de derecho marítimo, a las leyes y prácticas de intercambios culturales y a otros acuerdos y normas internacionales que regulen la protección de estos objetos. A la fecha, esta Convención cuenta con 167 Estados Parte, habiendo España ratificado el 15 de enero de 1997. Colombia no es Estado Parte, sin embargo algunas disposiciones le aplican por vía de costumbre internacional ${ }^{7}$.

En el 2001, la UNESCO en su reunión número 31, aprueba la "Convención sobre la Protección del Patrimonio Cultural Subacuático”. Este instrumento empieza por definir qué debe entenderse por este tipo de patrimonio, al indicar que comprende "todos los rastros de existencia humana que tengan un carácter cultural, histórico o arqueológico, que hayan estado bajo el agua, parcial o totalmente, de forma periódica o continua, por lo menos durante 100 años"8. Asimismo, esta Convención refiere las actividades y obligaciones que surgen para los Estados Parte sobre el PCS, según la porción de mar en

${ }^{4}$ Convención de la UNESCO sobre la Protección del Patrimonio Mundial, Cultural y Natural de 1972. Artículo 1.

${ }^{5}$ Convención de la UNESCO sobre las Medidas que deben Adoptarse para Prohibir e Impedir la Importación, la Exportación y la Transferencia de Propiedad Ilícitas de Bienes Culturales de 1970. Ver artículo 1 para definición de bienes culturales.

${ }^{6}$ La Convención, que está encaminada a la protección de los bienes culturales en el contexto de un conflicto armado, define los bienes culturales en su artículo 1. Convención de la UNESCO para la Protección de los Bienes Culturales en caso de Conflicto Armado de 1954.

${ }^{7}$ Así lo afirmó la Corte Internacional de Justicia en la sentencia de fondo del caso de Disputa Territorial y Marítima de Nicaragua c. Colombia (International Court of Justice, Territorial and Maritime Dispute (Nicaragua v. Colombia), Judgment of 19 November 2012, parrs. 114, 117, 118 and others).

${ }^{8}$ Convención de la UNESCO sobre la Protección del Patrimonio Cultural Subacuático de 2001. 
la que se encuentre (a partir de las divisiones dadas por CONVEMAR) 9 . Por ejemplo, el artículo 10 regula el procedimiento a seguir en caso de que ocurra el descubrimiento de PCS en la zona económica exclusiva o plataforma continental de un Estado Parte. Por otro lado, si este patrimonio se encuentra en la "zona”, el criterio de jurisdicción ya no aplica, y se hará un trabajo coordinado entre los Estados Parte, dando aplicación a lo dispuesto por el artículo 149 de CONVEMAR. Es sin embargo esta última perspectiva encaminada a la protección del PCS en beneficio de la humanidad, y no tanto la de la soberanía de los Estados, el propósito principal de la Convención, lo que se refleja no solo en sus principios ${ }^{10}$, sino en su "anexo" que contiene las normas respecto de las actividades relacionadas y dirigidas a este patrimonio. A agosto de 2015 la Convención cuenta con 51 ratificaciones, incluyendo la de España, Estado para el que entró en vigor la Convención el 2 de enero de $2009^{11}$. Colombia no es Estado Parte y no ha manifestado su interés en ratificarla ${ }^{12}$.

Por su parte, en la legislación colombiana existe una normativa especial que regula el PCS, y lo define como todos los "bienes producto de la actividad humana, que sean representativos de la cultura que se encuentran permanentemente sumergidos en aguas" 13 colombianas, por más de 100 años.

Para determinar qué constituye PCS en Colombia, el Consejo Nacional de Patrimonio Cultural ${ }^{14}$ partiendo de la definición dada en el artículo 2 de la Ley 1675, aplica a cada bien por categorizar los criterios de representatividad ${ }^{15}, \operatorname{singularidad}^{16}$, repetición ${ }^{17}$,

${ }^{9}$ Convención de Naciones Unidas sobre el Derecho del Mar de 1982.

${ }^{10}$ Vigni, P., "Historic Shipwrecks and the Limits of the Flag State Exclusive Rights", en Silvia Borelli, Federico Lenzerini (Edit.), Cultural Heritage, Cultural Rights, Cultural Diversity. New Developments in International Law, Martinus Nijhoff Publishers, Leiden-Boston, 2012. p. 291.

${ }^{11}$ Ver supra nota 8, artículo 27.

12 En el trámite interno para la ratificación del tratado, el texto no pasó la etapa de aprobación en la que se alegó una afectación a la soberanía del Estado colombiano, al derivarse de la Convención, de acuerdo con el Congreso de la República, que los bienes del navío pertenecen al Estado del pabellón y no al Estado en cuyo territorio se encuentren. Ver: Bernal, J. \& Contreras, C., "Unidad Coordinadora de Asistencia Técnica Legislativa, Ley 1147 de 2007”, en Congreso de la República de Colombia, Aquí Vive Colombia, Colombia, 2011, en http:/www.camara.gov.co/portal2011/comisiones/especiales/modernizacion/ unidad-asistencia-tecnica-legislativa.

${ }^{13}$ Ley 1675 de 2013, artículo 2. De acuerdo con el mismo artículo, se entiende que las "especies náufragas" son el género y el PCS una de sus especies.

${ }^{14}$ Institución que pertenece al Sistema Nacional de Patrimonio Cultural de la Nación, encargada de asesorar al Gobierno Nacional sobre la protección y manejo del patrimonio cultural (Ley 397 de 1997 , artículos 5 y 7). Frente a los bienes extraídos de las aguas colombianas, determina por medio de resolución, cuáles de los hallazgos constituyen patrimonio cultural de la nación y cuáles no (supra nota 13, artículo 14).

15 "Cualidad de un bien o conjunto de bienes, por la que resultan significativos para el conocimiento y valoración de particulares trayectorias y prácticas socioculturales que hacen parte del proceso de conformación de la nacionalidad colombiana, en su contexto mundial" (supra nota 13, artículo 3).

16 "Cualidad de un bien o conjunto de bienes, que los hace únicos o escasos en relación con los demás bienes conocidos, relacionados con las particulares trayectorias y prácticas socioculturales, de las cuales dichos bienes son representativos" (supra nota 13, artículo 3).

17 "Cualidad de un bien o conjunto de bienes muebles por la cual resultan similares, dadas sus características, su condición seriada y por tener valor de cambio o fiscal, tales como monedas, lingotes de 
estado de conservación ${ }^{18}$ e importancia científica y cultural ${ }^{19}$. El alcance de los criterios de repetición y de singularidad llevó al cuestionamiento de su consecuencia práctica al generar una posible división del patrimonio cultural, pues permite que una porción de los bienes sea categorizada como PCS y la otra quede excluida de dicha clasificación. Este debate fue resuelto por la Corte Constitucional colombiana, indicando que la decisión del Consejo Nacional de Patrimonio Cultural debe estar guiada por los cinco criterios en conjunto, contemplados en la Ley 1675. Específicamente, indicó que el criterio de repetición se debe analizar de manera concordante con el principio de unidad ${ }^{20}$, y en todo caso, siempre "deberá reservarse una muestra representativa del material y bienes extraídos que no constituyan [PCS] bajo el concepto de repetición” ${ }^{21}$. En el caso de fraccionamiento de los bienes encontrados, aquellos que son declarados como PCS hacen parte de la categoría de patrimonio arqueológico ${ }^{22}$, y como tal, pertenecen a la nación, tienen el carácter de inalienables, imprescriptibles e inembargables ${ }^{23}$. Por tanto, todas las actividades y operaciones que busquen su recuperación, requieren de autorización del Estado y de la celebración de un contrato ${ }^{24}$, por medio del cual se fijará la respectiva remuneración por las labores a realizar. Los bienes que no son parte del patrimonio arqueológico de la nación son de disposición autónoma del Estado colombiano e incluso puede comercializarlos ${ }^{25}$.

De otro lado, si bien en la legislación española no hay una ley específica sobre PCS que contemple una definición para este concepto, de acuerdo con la Ley 16 de 1985 sobre patrimonio histórico, hacen parte del patrimonio arqueológico todos "los bienes muebles o inmuebles de carácter histórico, susceptibles de ser estudiados con metodología arqueológica, hayan sido o no extraídos, y tanto si se encuentran en la superficie o en el subsuelo, en el mar territorial o en la plataforma continental" ${ }^{26}$. Así, se puede afirmar

oro y plata o piedras preciosas en bruto" (supra nota 13, artículo 3). La Corte Constitucional declaró su exequibilidad condicionada, ver sentencia C-264 de 2014.

18 "Grado de integridad de las condiciones físicas de los materiales, formas y contenidos originales que caracterizan a un bien o conjunto de bienes muebles e inmuebles, incluidos los contextos espaciales en los que se encuentran" (supra nota 13, artículo 3).

19 "Potencial que ofrece un bien, o conjunto de bienes muebles o inmuebles, de aportar al mejor conocimiento histórico, científico y cultural de particulares trayectorias y prácticas socioculturales que hacen parte del proceso de conformación de la nacionalidad colombiana, en su contexto mundial" (supra nota 13 , artículo 3).

${ }^{20}$ Ley 397 de 1997, artículo 4.

${ }^{21}$ Corte Constitucional de Colombia, sentencia C-264 de 2014, apartado 6.3.

22 De acuerdo con el artículo 2 de la Ley 1675 de 2013, "El Patrimonio Cultural Sumergido, de conformidad con lo previsto en los artículos 63 y 72 de la Constitución Política, hace parte del patrimonio arqueológico y es propiedad de la Nación”.

23 Supra nota 20 , artículo 6.

${ }^{24}$ Supra nota 13 , artículo 10.

25 Supra nota 21.

${ }^{26}$ Ley 16/1985, de 25 de junio, del Patrimonio Histórico Español, artículo 40 (subrayado por fuera del texto). 
que los bienes que constituyen PCS como parte del patrimonio arqueológico son de dominio público ${ }^{27}$.

En una lógica proteccionista, las disposiciones españolas sobre navegación marítima son claras al excluir la aplicación de las normas de salvamento y naufragios, cuando se trata de PCS. En caso de que este patrimonio se encuentre en mar territorial y aguas interiores españolas, cualquier extracción requerirá autorización de las autoridades o contrato público, siendo aplicable la legislación de patrimonio histórico y cultural. Ahora bien, cuando el PCS se encuentre en la zona contigua, zona económica exclusiva o la plataforma continental, se regirá por la Convención de la UNESCO sobre la Protección del Patrimonio Cultural Subacuático ${ }^{28}$.

Esto último diferencia la legislación española de la colombiana en materia de PCS, ya que España parte del criterio del Estado del pabellón para determinar la propiedad sobre las embarcaciones y su cargamento (que puede constituir PCS) ${ }^{29}$, y no del territorio del Estado en cuyas aguas se encuentren dichos bienes. Esta última posición es adoptada por Colombia.

Es importante aclarar que para el caso español, sean considerados o no patrimonio cultural subacuático, todas las naves del Estado naufragadas y su cargamento tienen carácter de bienes de dominio público estatal, lo que los hace inalienables, imprescriptibles, inembargables y gozar de inmunidad de jurisdicción ${ }^{30}$.

Dadas así las cosas, para el caso hipotético se presentaría una situación de doble reclamación de propiedad sobre la embarcación y el cargamento, que para efectos del caso colombiano y en aplicación de la Ley 1675 constituyen PCS de la Nación, y para el caso Español, a partir de la Ley de navegación marítima 14 de 2014, serían, por lo menos, bienes de dominio público estatal.

\section{Inmunidad jurisdiccional de los Estados}

Conforme lo dispuso por la Corte Internacional de Justicia $(\mathrm{CIJ})^{31}$ en su reciente sentencia relativa a inmunidad de jurisdicción, la inmunidad de los Estados que prohíbe ser demandados en cortes de otros Estados, o que se realicen medidas coercitivas sobre sus bienes, encuentra sustento en dos principios del derecho internacional, la igualdad soberana de los Estados ${ }^{32}$ y la no intervención en sus asuntos internos. Puede afirmarse

${ }^{27}$ Ibidem, artículo 44.

${ }^{28}$ Ley 14/2014, de 24 de julio, de Navegación Marítima, artículos 358, 369 y 383.

${ }^{29}$ Ibidem, artículo 382.

30 El artículo 382 de la Ley de Navegación Marítima de 2014, dispone que "cualquiera que sea el momento en que se produjo su pérdida y el lugar en que se encuentren, los buques y embarcaciones de Estado españoles naufragados o hundidos, sus restos y los de sus equipos y carga, son bienes de dominio público estatal, inalienables, imprescriptibles e inembargables y gozan de inmunidad de jurisdicción”.

${ }^{31}$ International Court of Justice, jurisdictional immunities of the state (Germany v. Italy: Greece intervening) judgment of 3 February 2012, párr. 57.

${ }^{32}$ Ver: Resolución 2625 de 1970 de la A.G/NU. 
igualmente, que la máxima de par in parem non habet jurisdictionem/imperium-raciocinio detrás de la figura en estudio- ${ }^{33}$, refleja los conceptos de los principios generales del derecho internacional referidos.

Esta figura, que abarca tanto la inmunidad de jurisdicción como la de ejecución de los Estados, ha evidenciado mediante la práctica de los Estados y la convicción jurídica, su constitución como fuente obligatoria del Derecho Internacional ${ }^{34}$. Si bien existen varios intentos en el escenario internacional para regularla, en la práctica lo que ocurre es la aplicación de la ley del foro y, por tanto, es esta la determinante sobre su alcance ${ }^{35}$.

Respecto a los intentos internacionales de regulación, encontramos en el escenario regional, la Convención de Bruselas de 1926 para la "Unificación de ciertas Reglas relativas a la Inmunidad de Barcos Estatales", la "Convención Europea sobre Inmunidad Estatal” de 1972, y el Proyecto Interamericano de la Convención sobre Inmunidades Jurisdiccionales de los Estados de $1983^{36}$. A nivel universal está la Convención de las Naciones Unidas sobre Inmunidades Jurisdiccionales de los Estados y de sus Bienes" de $2004^{37}$.

En 1991 la Comisión de Derecho Internacional (CDI), presentó a la Asamblea General de la ONU, el texto aprobado del Proyecto de Artículos sobre Inmunidades Jurisdiccionales de los Estados y su Propiedad, donde presenta la definición, el ámbito de aplicación, las situaciones en las que la inmunidad no puede ser invocada, las categorías de propiedad del Estado, entre otros temas. En los comentarios a los distintos artículos, además de indicar la interpretación que se debe dar a las disposiciones y materias reguladas, la Comisión hace referencia al tratamiento que los Estados han dado a esta figura desde la jurisprudencia y la normatividad interna. Así, se ha podido determinar que existen varios Estados que acogen una perspectiva restrictiva de la inmunidad de jurisdicción. Esto es, que no existe una inmunidad absoluta para los Estados, sino que existen ciertos actos que están excluidos de ella. Si bien esta posición restrictiva no ha mostrado ser costumbre internacional $^{38}$, sí fue acogida tanto en el Proyecto de la Comisión como en la Convención de la ONU de 2004.

${ }^{33}$ Gaukrodger, D., "Foreign State Immunity and Foreign Government Controlled Investors", OECD Working Papers on International Investment, 2010/02, OECD.

${ }^{34}$ Así lo reconoce no solo la CIJ en la sentencia de inmunidades de jurisdicción, sino también la Comisión de Derecho Internacional, que desde 1980 ha reconocido su carácter de derecho internacional consuetudinario. Supra nota 31, párr. 55 y ss; International Law Commission, Yearbook of the International Law Commission 1980, United Nations, New York, 1981, p. 144, párr. 126, respectivamente.

35 Supra nota 33.

36 International Law Commission, "Draft Articles on Jurisdictional Immunities of States and their Property, with commentaries”, 1991, parrs. 22,23.

${ }^{37}$ Esta Convención que regula la aplicación y el alcance de la figura bajo examen, requiere de 30 ratificaciones, aceptaciones, aprobaciones o accesiones para entrar en vigor. A 2015 esto no ha ocurrido, restando aún por lo menos 12 Estados más que decidan ser parte del tratado para que la Convención entre en vigor.

${ }^{38}$ En el tercer capítulo de este artículo se hará referencia con mayor detenimiento a los actos que excluyen la inmunidad de jurisdicción y ejecución. 
Finalmente, en cuanto a los ordenamientos internos, por una parte, es importante resaltar que Colombia por medio de la jurisprudencia constitucional reconoce y aplica en su ordenamiento jurídico la costumbre internacional relativa a la inmunidad jurisdiccional y de ejecución, aceptando que su contenido y alcance se encuentra en la mencionada Convención de inmunidades jurisdiccionales ${ }^{39}$. A partir de la decisión de la Corte Constitucional del $2013^{40}$, se concluye que Colombia acoge la perspectiva restrictiva de esta figura jurídica.

Por otra parte, España por medio de disposiciones normativas ${ }^{41}$, como Estado Parte de la referida Convención y por la jurisprudencia del Tribunal Constitucional ${ }^{42}$, reconoce y aplica la figura de la inmunidad de jurisdicción y ejecución desde la perspectiva restrictiva. Esta postura se evidencia en la práctica de España en casos específicos respecto de pecios de Estados extranjeros encontrados en aguas españolas ${ }^{43}$, y en la práctica de Estados extranjeros, que en virtud del principio de reciprocidad, han reconocido la propiedad del Estado español acerca de pecios puestos en conocimiento de tribunales nacionales ${ }^{44}$.

\section{II. ¿Dilusión DE LOS INTERESES ESPAÑOLES EN EL CASO HiPOTÉTICO?}

A partir del caso hipotético referido en la introducción, así como de las disposiciones de derecho internacional e interno estudiadas, tenemos que la embarcación y el cargamento cumplen con las características para ser considerados patrimonio cultural subacuático. ¿Qué ocurre si España alega que el cargamento constituye PCS español, que por tanto debe serle entregado y que toda actividad que se pretenda realizar sobre

${ }^{39}$ La Corte Constitucional plantea que si bien Colombia al no haber ratificado la Convención de las Naciones Unidas sobre inmunidades de los Estados y de sus bienes, no se encuentra obligada por este instrumento, acude a su texto para definir el alcance y aplicación de la figura de inmunidad de jurisdicción y de ejecución (Corte Constitucional de Colombia, sentencia T-901 de 2013).

${ }^{40} \mathrm{La}$ Corte Constitucional dispuso que "la interpretación de la inmunidad jurisdiccional como un principio absoluto es insostenible en un estado constitucional de derecho como el colombiano (...) con ello, se refuerza la imperiosa necesidad de acoger el principio de inmunidad jurisdiccional desde una perspectiva relativa”. Ibidem.

${ }^{41}$ Ley Orgánica 6/1985, de 1 de julio, del Poder Judicial, artículo 21; supra nota 28, artículo 366.

42 Tribunal Constitucional de España, Sala Segunda. Sentencia 107/1992, de 1 de julio de 1992.

${ }^{43}$ La recuperación de la embarcación británica Sussex por la empresa Odyssey Marine Exploration, en aguas españolas, originó que las autoridades españolas impusieron una multa a dicha empresa por realizar actividades arqueológicas sin autorización. Sin embargo, reconocieron la titularidad británica sobre el pecio y por ende no tomaron medida alguna sobre los objetos recuperados (Sala de lo Contencioso Administrativo del Tribunal Superior de Justicia de Andalucía, con sede en Sevilla, sentencia de 26 de mayo de 2010).

${ }^{44}$ Como se expondrá posteriormente, ejemplos de casos que hacen parte de esta práctica son La Galga y Juno, embarcaciones encontradas en aguas estadounidenses en las que se reconoció la propiedad española (US Court of Appeals for the 4th Circuit, Sea Hunt Incorporated and Commonwealth of Virginia vs. The Unidentified Shipwrecked vessel and cargo, in rem, Kingdom of Spain, et al., July 21, 2000). Y Las Mercedes, referido en la introducción (US Court of Appeals for the 11th Circuit, Odyssey Marine Exploration, INC. v. The Unidentified Shipwrecked vessel, and cargo, in rem, Kingdom of Spain, et al., September 21, 2011). 
este patrimonio debe ser autorizada por España? ${ }^{45}$ A la luz de la legislación aplicable, ¿tiene España alguna oportunidad de "recuperar su” PCS?

Si bien la Convención de la UNESCO sobre PCS podría ser aplicable por la materia de la que trata, hay que recordar que solo España y no Colombia es Estado Parte de la Convención, y que no se ha formado a la fecha costumbre internacional concerniente a sus disposiciones. Por tanto, no podría ser invocada para efectos de este caso.

Ahora bien, debido a que la embarcación y su cargamento se encuentran en territorio colombiano, la ley del foro será la de dicho país. Al ser estos bienes muebles sobre los que esta nación tiene un interés -y afirmará después, un derecho en aplicación de la Ley 1675 de 2013-, procede la aplicación de su propia legislación, conforme a su Código Civil ${ }^{46}$.

En todo caso de acuerdo con la Convención de la UNESCO, cuando el PCS se encuentre en aguas interiores, aguas archipelágicas y mar territorial, se reconoce el ejercicio de la soberanía de los Estados, en virtud del criterio espacial y no del criterio del Estado del pabellón ${ }^{47}$. Por tanto España, que es Estado Parte, no podría desconocer la Convención, mediante ella se llega a la misma conclusión, es decir, se reconoce la legislación colombiana como la ley aplicable.

En consecuencia, desde este escenario España carece de mecanismos jurídicos para "recuperar" lo que considera como PCS de su propiedad. Tal vez esto explique la actitud pasiva que ha tomado dicho Estado para recuperar por medio de actuaciones judiciales este tipo de bienes ${ }^{48}$.

\section{INMUNIDAD JURISDICCIONAL: ¿POSIBLE SOLUCIÓN PARA ESPAÑA?}

Una vía jurídica alternativa para España frente a este tipo de escenarios parece ser la aplicación de la figura de inmunidad de jurisdicción o de ejecución. Para que esta figura opere, se requiere como presupuesto lógico la activación de la jurisdicción de un tercer Estado, que sea competente, para conocer de un caso en contra de España,

45 Supra nota 30. Adicionalmente, el pecio constituye PCS para la legislación española, con base en la definición dada por la Ley de Patrimonio Histórico (supra nota 26, artículo 40) y aquella establecida en la "Convención sobre la Protección del Patrimonio Cultural Subacuático", ambas referidas en el capítulo I de este artículo.

${ }^{46}$ De acuerdo con el artículo 20 del Código Civil colombiano, "los bienes situados en los territorios, y aquellos que se encuentren en los Estados, en cuya propiedad tenga interés o derecho la Nación, están sujetos a las disposiciones de este Código, aun cuando sus dueños sean extranjeros y residan fuera de Colombia”.

${ }^{47}$ El artículo 7 de la Convención de la UNESCO de 2001, dispone que "En el ejercicio de su soberanía, los Estados Partes tienen el derecho exclusivo de reglamentar y autorizar las actividades dirigidas al patrimonio cultural subacuático en sus aguas interiores, aguas archipelágicas y mar territorial" (supra nota 8, artículo 7).

${ }^{48}$ El caso de la embarcación de Nuestra Señora de Atocha, refleja lo expresado. En este, los tribunales de Estados Unidos le asignan la titularidad de los bienes rescatados a la empresa Treasure Salvors, Inc. (Supreme Court of the US, Florida Department of State v. Treasure Salvors, Inc., July 1, 1982). Sin embargo, España permanece indiferente frente a este proceso judicial, para proceder posteriormente a adquirir parte de los bienes en mención en subasta pública (supra nota 3, pp. 103 y 104). 
o el ejercicio de una medida coercitiva sobre propiedad española ${ }^{49}$. Para ilustrar esta afirmación, traemos a colación los casos de las fragatas Juno y La Galga, así como el caso de Las Mercedes.

En el primer caso, España intervino alegando que era el propietario de buena fe de las fragatas, y que nunca había abandonado, renunciado o transferido sus derechos sobre dichos bienes. Los tribunales estadounidenses encontraron que España era el legítimo propietario de ambas embarcaciones ${ }^{50}$. En el segundo caso, España alega inmunidad soberana sobre la fragata de su propiedad, frente a ello la Corte del Distrito Medio de Florida y la Corte de Apelaciones del Décimo Primer Circuito, reconocieron que al ser la embarcación de propiedad española, tenía aplicación la figura de inmunidad soberana y por tal razón estos tribunales no tenían jurisdicción para decidir el fondo del caso ${ }^{51}$. En este tema, frente a la acción in $\mathrm{rem}^{52}$ interpuesta por la empresa de salvamento en contra del pecio, España presentó una moción alegando inmunidad de ejecución frente al secuestro de los bienes de su propiedad (Las Mercedes y su carga). Estados Unidos intervino en apoyo a la posición española, afirmando la necesidad del cumplimiento del principio de reciprocidad expuesto en un tratado bilateral existente entre ambos Estados $^{53}$. La Corte del Distrito concluyó ${ }^{54}$ que la embarcación era española, y que operaba la inmunidad de ejecución, por cuanto en su opinión, la embarcación estaba realizando un acto de soberanía y no comercial al transportar el cargamento de propiedad principalmente de particulares. Esto, porque a la fecha de la ocurrencia de los hechos las fragatas españolas realizaban el transporte de este tipo de cargamento en cumplimiento de una función estatal consistente en proveer protección y paso seguro a la propiedad de sus ciudadanos en tiempos de guerra o amenaza de guerra ${ }^{55}$.

Para analizar si en nuestro caso hipotético procedería una inmunidad de jurisdicción o de ejecución, y si su aplicación llevaría a que España obtuviera la propiedad sobre el cargamento de su embarcación constitutivo de PCS, debemos empezar por referir el alcance de la inmunidad jurisdiccional y su estatus jurídico internacional y nacional.

\section{Alcance de la figura}

La jurisdicción es un concepto jurídico que hace referencia a la capacidad de administrar justicia. Esta figura relacionada con principios del derecho internacional

\footnotetext{
${ }^{49}$ En este sentido, comentario 1 del párrafo 1 del artículo 6 del documento (supra nota 36).

${ }^{50}$ Caso La Galga y Juno, supra nota 44.

51 Caso Las Mercedes, supra nota 2 y 44.

52 Supra nota 2.

${ }^{53}$ En virtud de este tratado, Estados Unidos se comprometía a otorgar el mismo tratamiento a España, que el dado por esta a embarcaciones de guerra estadounidenses hundidas, concediento protección e inmunidad frente a normas sobre abandono implícito y de salvamento. Ver: Crook, J., "Contemporary Practice of the United States relating to International Law, State Jurisdiction and Immunities", en American Journal of Internationa Law, vol. 106, núm. 1, enero de 2012, p. 149-153.

${ }^{54}$ Esta decisión fue apelada y confirmada en apelación. Ver: Caso Las Mercedes, supra nota 44.

55 Supra nota 53, p. 149-153.
} 
como el respeto por la integridad territorial y la independencia política de los Estados, refiere a nivel interno que existe un ámbito espacial en donde el Estado puede ejercer esa capacidad de manera soberana ${ }^{56}$. Sin embargo, y en reconocimiento de los mismos conceptos que la estructuran, esta jurisdicción tiene limitantes, como por ejemplo la inmunidad de jurisdicción y ejecución de los Estados. Desde esta limitación, los Estados no pueden ser demandados, ser parte en un proceso doméstico o sus bienes ser objeto de medidas coercitivas por otro Estado, a menos que hayan dado su autorización para estos efectos. En principio, durante los siglos XVIII y XIX, la inmunidad de los Estados era vista como absoluta; esto es, que por ninguna razón el Estado podía ser llevado ante cortes domésticas de un tercer Estado. Esto obedece a que para los siglos referidos la influencia del concepto del Estado absoluto de Bodin no podía dar lugar a una posición distinta en la que la soberanía del Estado pudiera verse intervenida de alguna manera ${ }^{57}$. A inicios del siglo XX, con el incremento de la participación de los Estados en actividades de connotación privada, como actividades comerciales ${ }^{58}$, el concepto absoluto de la inmunidad de jurisdicción empezó a ver matices exigibles por los particulares que se vieron en una posición de desventaja. Esta era evidente, pues toda controversia judicial entre una persona jurídica privada y una pública de un Estado extranjero llevaría a que el particular se sometiera, necesariamente, a las cortes del Estado con el que se presentaba la disputa. En razón a esta realidad, surge la segunda perspectiva, que es conocida en la doctrina y jurisprudencia nacional e internacional como la posición restrictiva. De acuerdo con esta posición, la inmunidad de jurisdicción de los Estados procede solo cuando estos realizan actos derivados de su soberanía (acta jure imperii). En consecuencia, cuando el Estado realiza actos que no son propios de su soberanía, como actos de comercio o relacionados con el derecho privado (acta jure gestionis), no puede acertar un alegato o defensa basado en la inmunidad de jurisdicción ${ }^{59}$.

Debe entenderse que este concepto de inmunidad de los Estados se refiere tanto a la jurisdicción como a la ejecución. En este sentido, es importante comprender que a la luz del Proyecto de la CDI, así como de la Convención de la ONU sobre inmunidades, esta figura abarca todo el proceso judicial, esto es, no solo lo relacionado con la determinación de la competencia, la instauración de los procedimientos, la investigación, el juicio, etc., sino también lo relacionado con medidas coercitivas ejercidas sobre la propiedad del Estado $^{60}$. En este sentido, la inmunidad de jurisdicción en términos amplios abarcaría tanto la de jurisdicción propiamente dicha como la de ejecución, siendo sin embargo dos fases distintas de la inmunidad de los Estados. La primera, referida a la adjudicación del litigio, y la segunda, a las medidas coercitivas que se imponen sobre los bienes del Estado como la incautación, secuestro, ejecución, entre otras ${ }^{61}$.

\footnotetext{
${ }^{56}$ Shaw. M., International Law, Cambridge University Press, Nueva York, 2003, p. 621.

${ }^{57}$ Fox. H., The Law of State Immunity, Oxford University Press, Oxford, 2003, p. 26.

58 Supra nota 56, p. 625.

59 Ídem.

${ }^{60}$ Ver párrafo 2 del comentario del artículo 1 supra nota 36.

${ }^{61}$ Ver párrafos 1, 2 y 4 del comentario del artículo 18 del documento: supra nota 36.
} 
Ahora en cuanto al reconocimiento que le han dado los Estados a esta figura, si bien existe costumbre internacional respecto de la inmunidad de jurisdicción (en sentido amplio) de los Estados, no puede afirmarse lo mismo respecto de la posición absoluta o restrictiva; aunque sí existe evidencia de una importante acogida de la posición restrictiva. En 1991 la CDI realizó una revisión de los Estados que acogían esta posición bien por vía normativa, bien por vía jurisprudencial. En este sentido, evidenció la existencia de práctica estatal que corrobora la adopción de la perspectiva restrictiva por algunos Estados ${ }^{62}$. Esta inclinación se reitera con ocasión de las negociaciones de la Convención de las Naciones Unidas sobre Inmunidades Jurisdiccionales. Para el 2004 los negociadores del texto del tratado acogen la perspectiva restrictiva. A la fecha, hay 28 Estados signatarios y 18 Estados Parte de esta Convención, incluyendo en ambos grupos a Estados que para 1991 no habían tomado una posición restrictiva, bien por falta de referencia a ella, bien por aplicación en sus Cortes de la perspectiva absoluta ${ }^{63}$.

Cuando los Estados deciden acoger la posición restrictiva están afirmando que existen unas situaciones en las que procederá la inmunidad del Estado y otras en las que, por el contrario, el Estado será llevado ante las Cortes de otro Estado, o se ejercerán medidas coercitivas acerca de su propiedad. Para efectos de determinar cuándo procede la inmunidad y cuándo no, deben existir unos criterios determinadores. Mediante el ejercicio de las Cortes nacional e internacional, se ha decantado un criterio determinador central, que consiste en el acto que ejerce el Estado. Si este es propio de la soberanía del Estado (acta imperii), la inmunidad se mantiene intacta; si, por el contrario el acto no implica una actividad soberana, no habrá lugar a aplicación de la inmunidad ni de jurisdicción ni de ejecución (acta gestioni). Este criterio de determinación para la procedencia o no

${ }^{62}$ Por vía jurisprudencial: Italia, Bélgica, Egipto, Alemania, Estados Unidos, el Reino Unido, Francia, el Reino de los Países Bajos, Australia, Pakistán y Argentina. Supra nota 3. A su vez, por vía normativa: Estados Unidos con el Estatuto de Inmunidades Soberanas Extranjeras de 1976; el Reino Unido con el Estatuto de Inmunidad Estatal de 1978; Canadá con el Estatuto de Inmunidad Estatal de 1978; Singapur con el Estatuto de inmunidad Estatal de 1979; Pakistán con la Ordenanza de la Inmunidad Estatal de 1981; Sudáfrica con el Estatuto de la Inmunidad del Estado Extranjero de 1981; Malasia con el Estatuto de Inmunidades y Privilegios de 1984; Australia con el Estatuto de Inmunidades Soberanas Extranjeras de 1985 y Argentina con la Ley \# 24,488 del 31 de mayo de 1995.

63 En la lista de Estados signatarios que no se encuentran incluidos en el estudio realizado por la CDI, para 1991, están China (2005), Dinamarca (2006), Eslovaquia (2005), Estonia (2006), India (2007), Islandia (2005), la Federación Rusa (2006), Madagascar (2005), Marruecos (2005), México (2006), Paraguay (2005), Senegal (2005), Sierra Leona (2006), Timor Oriental (2005). Por su parte, la lista de los Estados que no habiendo sido referidos por la Comisión son parte de la Convención, se conforma por Arabia Saudita (2010), Austria (2006), España (2011), Finlandia (2014), Japón (2010), Kazajstán (2010), Letonia (2014), Líbano (2008), Lichtenstein (2015), Noruega (2006), Portugal (2006), República Checa (2015), República Islámica de Irán (2008), Rumania (2007), Suecia (2009), Suiza (2010). Información disponible en: https:// treaties.un.org/pages/ViewDetails.aspx?src=TREATY\&mtdsg_no=III-13\&chapter=3\&lang=en. Existen sin embargo Estados que mantienen la posición absoluta. Así lo refiere por ejemplo Gaukrodger, respecto de Bulgaria, República Checa, Polonia, Rumania y Rusia como Estados que aplican el criterio absoluto. Supra nota 33, p. 11. Sin embargo para el 2015 dos de esos Estados (República Checa - 2015 y Rumania - 2007) han ratificado la Convención. Para mayor información sobre Estados que aplican la posición absoluta, ver Bankas. E., The State Immunity Controversy in International Law, Srpinger, Berlin-Heidelberg, 2005. 
de la inmunidad ha sido acogido por varios Estados, así como por la CIJ, que además señaló, a partir de la práctica de los Estados, como actividades no soberanas "aquellas de orden privado y comercial" ${ }^{4}$. La Convención de la ONU de 2004, a partir de sus artículos 5 y 10, también acoge este criterio determinador. De los Estados que han hecho referencia expresa a este criterio, encontramos por ejemplo a Italia con el caso Banco de la Nación vs. Credito Varesino en el que la Corte de casación determinó que las transferencias monetarias hechas por un banco italiano a favor de un banco peruano implican actividades de naturaleza privada y por tanto no procede la inmunidad ${ }^{65}$. Igualmente está Bélgica, en el caso Société pour la fabrication des cartouches vs. Col. M., Ministre de la Guerre de Bulgarie, en el que se negó la inmunidad al considerar que la compra de armas o municiones es un acto iure gestionis ${ }^{66}$. El caso V. Stukonis vs. US embassy, 1998, en el que la Corte Suprema de Lituania refiere las diferencias entre los actos de iure imperri y los de iure gestioni ${ }^{67}$. Y, entre otros, el caso 107 del Tribunal Constitucional de España de 1992, en el que al decidir respecto de un recurso de amparo en relación con medidas de ejecución sobre bienes de la República de Sudáfrica, afirma que solo operará la inmunidad sobre aquellos bienes "que estén destinados a la realización de actos iure imperii..." 68 .

La práctica estatal no ha sido uniforme en cuanto a la determinación de si el acto es soberano o no. En la mayoría de los casos se ha acudido a la naturaleza del acto para hacer esta categorización. Así, encontramos a favor de esta posición la actuación de los tribunales italianos ${ }^{69}$, estadounidenses ${ }^{70}$ y

${ }^{64}$ Supra nota 31, párr. 60. En el mismo sentido, Cortes del Distrito y del Circuito de estados como Columbia y Texas, han planteado que frente a actos comerciales realizados por el Estado no procede la inmunidad. Ver: US District Court, District of Columbia. Leonard Malewicz, et al., v. City of Amsterdam, .No. CIV.A. 04-0024(RMC). March 30, 2005. Practical Concepts, Inc. v. Republic of Bolivia, 811 F.2d 1543, 1549 (D.C.Cir.1987).

${ }^{65}$ Corte de Casación, Banco de la Nación v. Crédito Varesino, SpA, Italia, Caso No. 5275 (1984) 87 ILR 15.

66 Judicatura de Bélgica, Société pour la fabrication des cartouches vs. Col. M., Ministre de la Guerre de Bulgarie, 1889, citado en Lauterpacht E. (Ed.) International Law Collected papers, 3. The Law of Peace parts II-VI, Cambridge University Press, Cambridge, 1977, p. 351.

${ }^{67}$ Supreme Court of Lithuania, V. Stukonis vs. US embassy, 1998-01-05 LAT nutartis c.b. Nr. 3K-1/98, citado por Toleikytè, N., "The Concept of State Immunity and the Main Challenges", disponible en http:// www.tf.vu.lt/dokumentai/Admin/Doktorant\%C5\%B3_konferencija/Toleikyte.pdf

citando a Baleviciené, K., "Riboto valstybés imuniteto doktrina ir jos taikymas Lietuvos Respublikoje", Jurisprudencija, 2004, t. 58 (50); pp. 138-145.

68 Supra nota 42.

${ }^{69} \mathrm{La}$ Corte de apelaciones de Génova negó la inmunidad a Iraq en un proceso relativo a una disputa contractual con una empresa italiana que le suministraba barcos de guerra. La Corte sostuvo que no procedía la inmunidad por la naturaleza comercial del contrato, a pesar de que su propósito fuera de carácter público. La Corte de Casación italiana en el caso Borriloca vs. Argentina le otorgó inmunidad a Argentina en un litigio, por la ausencia de pago de unos bonos estatales a ciudadanos italianos, sosteniendo que la medida en virtud de que Argentina decide no pagar, se toma por medio de una ley. Esto implica un acto de naturaleza soberana. Sciso, E., “Italian Judges' Point of View on Foreign States'Immunity”, en Banderbilt Journal os Transnational Law, vol. 44, 2011, p. 1205.

${ }^{70}$ En el caso Altman vs. Austria, la Corte de Apelaciones del 9 Circuito de Estados Unidos niega la inmunidad a Austria, al aplicar el criterio de la naturaleza del acto que está consagrado en la ley estadounidense sobre inmunidades de Estados (FSIA), al encontrar que este país realizaba una actividad comercial con las 
alemanes $^{71}$. Con menor recurrencia se ha apelado al propósito del acto. En el caso AIG Capital Partners Inc. vs. Kazabistán, el tribunal inglés concedió la inmunidad a Kazahistán, al afirmar que este Estado realizaba un acto soberano al comercializar con activos del mercado de valores, en virtud a que el propósito de dicha actividad era de interés público y por tal razón hacía parte del ejercicio de la autoridad soberana ${ }^{72}$. Finalmente, se han presentado casos como el del I Congreso del Partido, en el que se acogen ambos criterios ${ }^{73}$.

\section{PCS como factor determinante para reconocer la inmunidad de ejecución}

A partir de la distinción entre los actos imperii y los actos gestioni, se ha dispuesto en el Proyecto de la CDI, así como en la Convención de la ONU de 2004, que las actividades que se ejerzan sobre el patrimonio cultural serán consideradas siempre de iure imperii. Los artículos 18 y 19 de la Convención refieren la inmunidad de ejecución, esto es, la imposibilidad de imponer medidas coercitivas sobre bienes de propiedad de un Estado extranjero. La regla general enunciada en ambos artículos es que no proceden dichas medidas frente a esta propiedad, a menos que el Estado haya consentido de manera expresa su adopción o que haya "asignado o destinado [esos] bienes a la satisfacción de la demanda objeto [del] proceso”, y adicional y exclusivamente para el caso del artículo 19 (medidas coercitivas posteriores al fallo), no procederá la inmunidad cuando los bienes se utilizan para actividades de iure gestioni ${ }^{74}$. A su vez, el artículo 21 de la Convención refiere una lista taxativa de bienes del Estado sobre los que se excluye la posibilidad de considerar que son usados para actos no soberanos. En otras palabras, todo acto realizado en relación con los bienes enlistados en el artículo 21 es de iure imperii y, por tanto, procederá la inmunidad de ejecución, a menos que se encuentre dentro de alguna de las dos excepciones en común consagradas en los artículos 18 y 19 de la Convención. El artículo 21.1 (d) incluye dentro de esa lista de bienes al patrimonio cultural de un Estado. En esta medida, si en una corte extranjera se pretenden imponer medidas coercitivas sobre bienes que constituyen PCS de otro Estado, este último tendrá la posibilidad jurídica

pinturas objeto de la controversia (US Court of Appeals for the 9th Circuit, Maria V. Altmann vs. Austria, and the Austrian Gallery, an agency of Austria, December 12, 2002). En igual sentido en el caso Guevara vs. Peru, en el que se demandó a Perú para que pagara una recompensa que había prometido por dar información sobre el paradero de un fugitivo, la Corte del 11 Circuito sostuvo que si bien el objetivo de capturar a un fugitivo es un acto de soberanía, la naturaleza de los medios empleados en dicho caso, es decir, ofrecer una recompensa a cambio de información, es en esencia comercial y por tanto no le otorga la inmunidad a Perú (US Court of Appeals for the 11th Circuit, José Guevara vs. Peru, Ministerio del Interior, et al., November 1, 2006).

${ }^{71} \mathrm{La}$ Corte Constitucional alemana, en el caso de Imperio de Irán, critica el uso del criterio del propósito de la transacción para determinar si un acto es iure imperii o iure gestionis. Así mismo, establece que una vez el Estado entra al mercado, la caracterización del acto como comercial permanece. Caso citado en supra nota 33.

72 Supra nota 33, p. 21-23.

73 Supra nota 33, p. 19.

${ }^{74}$ Es importante aclarar que el Proyecto de la Comisión no hacía distinción entre las medidas coercitivas anteriores al fallo y aquellas posteriores. Por tanto, el artículo 18 del Proyecto refiere las tres excepciones enunciadas que aplicarían en ambos escenarios, a diferencia de la Convención, para la que la tercera excepción, esto es, los actos de iure gestioni, solo aplican respecto de las medidas a imponer con posterioridad al fallo. 
de solicitar la inmunidad de ejecución frente a dichas medidas, teniendo que demostrar solamente que los bienes constituyen PCS de su propiedad, sin tener que entrar a argumentar respecto del tipo de acto (soberano o no soberano) que se realiza sobre esos bienes.

Finalmente, si bien el principal criterio para la aplicación de la posición restrictiva sería la distinción entre actos soberanos y no soberanos del Estado, y a su vez, el concepto del PCS para efectos de la inmunidad de jurisdicción va atado al tipo de acto conforme lo dispone el artículo 21 de la Convención, en la práctica se desprenden dos situaciones de este presupuesto, que vale la pena revisar.

La primera, es que tratándose de patrimonio cultural en general (donde se incluye el PCS), no se entraría a estudiar la actividad o el tipo de acto que realiza el Estado, sino a verificar el tipo de bien, puede afirmarse que esta disposición termina adicionando la naturaleza del bien como otro criterio determinante de la procedencia de la inmunidad de ejecución. En el caso Diag Human S.E. contra República Checa, resuelto por la Corte del Distrito de Viena en 2011, se aplicó el criterio del patrimonio cultural para conceder la inmunidad de ejecución. En este caso, el problema jurídico giró en torno a la aplicación de la inmunidad de ejecución frente bienes que hacen parte del patrimonio cultural de la nación checa. La Corte, observando las disposiciones de la Convención de la ONU sobre inmunidades (ratificada por Austria desde el 2006), determinó que la propiedad cultural de un Estado es inmune a medidas coercitivas adoptadas por tribunales de otro Estado y por tanto concedió la referida inmunidad ${ }^{75}$.

La segunda situación que se presenta en la práctica es que aunque existan disposiciones internacionales y nacionales, así como declaraciones que pueden ser consideradas como actos jurídicos unilaterales de $\operatorname{los} \operatorname{Estados}^{76}$, que confirmen al PCS como criterio determinador de la aplicación de la inmunidad de ejecución, uno de los puntos de partida (además de la existencia de un proceso judicial) es la demostración de la propiedad sobre ese PCS. En la práctica será muy difícil que un Estado reconozca que unos bienes hacen parte del PCS de otro Estado, cuando estos resultan significativos para el conocimiento y valoración de trayectorias y prácticas socioculturales que hacen parte del proceso de conformación de la nacionalidad de ambos Estados, como puede ocurrir en el caso de España y sus antiguas colonias ${ }^{77}$. Sin embargo, la legislación colombiana

75 Pavoni, R., "Sovereign Immunity and the Enforcement if International Cultural Property Law", en Francioni, F. \& Gordley, J. (Edit.), Enforcing International Cultural Heritage Law, Oxford University Press, Oxford, 2013, p. 99.

76 Supra nota 39, parrs. 18 y 22.

${ }^{77}$ Si bien la Convención de la UNESCO sobre PCS, no hace referencia expresa a un PCS compartido en el sentido de pertenecer a dos o más Estados, lo cierto es que reconoce que pueden existir vínculos culturales de varios Estados sobre los mismos bienes, que podrían llegar a ser PCS. La Convención sobre la protección del patrimonio mundial, cultural y natural de 1972, reconoce la posibilidad del patrimonio cultural compartido a partir de un criterio espacial del bien tangible, cuando su ubicación es transfronteriza. Así ocurre con varios de los bienes inscritos en la lista del patrimonio mundial, que son compartidos por ejemplo entre Francia y Bélgica, Polonia y Alemania, entre otros. Además de un criterio fronterizo, se entiende que el patrimonio cultural referido por la convención tienen un "valor universal excepcional”, conforme lo consagra el artículo 1, y que los bienes inscritos constituyen patrimonio mundial. Sin embargo, la discusión más allá 
abre una posibilidad para que España pueda acceder a una porción de esos bienes a partir de la aplicación de los criterios determinantes de PCS contenidos en el artículo 3 de la Ley 1675 de 2013, específicamente, el criterio de repetición en concordancia con la interpretación dada por la Corte Constitucional de Colombia ${ }^{78}$, bajo unos supuestos específicos que se explicarán a continuación.

\section{Aplicación al caso bipotético}

De acuerdo con lo anteriormente planteado, se pasa ahora a analizar cómo puede España acceder a bienes de PCS que se encuentran en territorio colombiano y que son considerados como propios tanto por Colombia como por España. Una de las posibles vías judiciales es la de la inmunidad de los Estados en su dimensión de ejecución y no de jurisdicción propiamente dicha, ya que esta última solo puede ser alegada por el Estado que es demandado. Para el caso hipotético que presentamos, por un lado, no se ve cómo España sería demandado, y por otro lado, si España pretendiera iniciar una acción judicial ante los tribunales colombianos, estaría renunciando a dicha inmunidad ${ }^{79}$.

Sin embargo, como ocurrió en el caso de Las Mercedes, podría proceder la inmunidad de ejecución que se presenta cuando hay un proceso judicial en el que así no se demande al Estado extranjero, sí se afecta o se busca afectar la propiedad de este Estado ${ }^{80}$. En tal

del concepto de patrimonio común de la humanidad o universal se viene dando a nivel doctrinal. En este sentido, encontramos la Declaración sobre el Patrimonio Cultural Submarino del Mar Mediterráneo, de 2001, en la que los declarantes reconocen que el patrimonio cultural mediterráneo representa las raíces culturales e históricas de muchas civilizaciones (declaración citada en Scovazzi, T., The Merits of the UNESCO Convention on the Protection of the Underwater Cultural Heritage, en Cultural Heritage, Cultural Rights, Cultural Diversity, New Developments in International Law, Martinus Nijhoff Publishers, Leiden, 2012, p. 276. El mismo autor, refiriéndose al patrimonio intangible, afirma que: "(...) el mismo patrimonio cultural intangible puede pertenecer al territorio de dos o más Estados si este tiene un carácter transfronterizo o incluso transcontinental” [traducción no oficial]. Scovazzi, T., The Definition of Intangible Cultural Heritage, en Cultural Heritage, Cultural Rights, Cultural Diversity, New Developments in International Law, Martinus Nijhoff Publishers, Leiden, 2012, p. 198). Igualmente, Jakubowski reconoce la posibilidad de un patrimonio cultural compartido entre dos o más Estados, al referir el fenómeno de la sucesión de Estados. En este sentido, propende por el "intercambio cultural a través de préstamos a corto plazo y depósitos bajo acuerdos a mediano o largo plazo" [traducción no oficial]. En este sentido, el autor, basándose en instrumentos y práctica internacional, propone un "Proyecto de Principios Guía en Relación con la Sucesión de Estados respecto al Patrimonio Cultural Tangible". Sin embargo, el autor excluye expresamente los Estados independizados, entre otras razones, por considerar superado el fenómeno del colonialismo (Jakubowski, A., "State Succession in Cultural Property", Oxford University Press, Nueva York, 2015, pp. 333-334 y Anexo). Es nuestra posición de que a pesar de que la independencia ya se haya logrado en algunos casos desde hace varios siglos o hace años, no implica esto que no surjan o no se mantengan discusiones sobre el patrimonio cultural, especialmente el PCS como en el caso hipotético planteado en este artículo, y muy común en la realidad, de embarcaciones españolas hundidas en territorio de alguna de sus antiguas colonias, y con cargamento proveniente de alguna de ellas.

78 Supra nota 13 , artículo 3; supra nota 21, apartado 6.2.

${ }^{79}$ Convención de las Naciones Unidas sobre las Inmunidades Jurisdiccionales de los Estados y de sus Bienes de 2004, artículo 6 numeral 1.

${ }^{80}$ Ibídem, artículos 18, 19 y 6, numeral 2 literal b. 
sentido, en el caso planteado y de acuerdo con el ordenamiento jurídico colombiano, España podría buscar la recuperación de lo que considera como su PCS por vías judiciales, y según las condiciones, solicitando la devolución de los bienes o haciendo uso de la inmunidad de ejecución frente a una medida judicial coercitiva.

Esto procederá a partir de la ley colombiana, así como del derecho internacional que en materia de inmunidades jurisdiccionales rige para Colombia. Si bien este Estado no tiene un Estatuto interno sobre inmunidades de jurisdicción y ejecución de los Estados, y tampoco ha ratificado la Convención de la ONU de 2004, la aplicación de esta figura en Colombia se da por dos vías. La primera es la costumbre internacional. De manera reiterada se ha reconocido a nivel internacional que la inmunidad de jurisdicción tiene el carácter de derecho internacional consuetudinario y Colombia nunca ha sido objetor persistente de esta costumbre ${ }^{81}$. En segundo lugar, la Corte Constitucional de Colombia en reiterada jurisprudencia ${ }^{82}$ ha reconocido esta figura jurídica como costumbre vinculante para el Estado, y ha desarrollado su contenido, estableciendo que en Colombia, como "Estado Constitucional de Derecho", tiene cabida la perspectiva restrictiva ${ }^{83}$. Finalmente, la Corte Constitucional ha llegado al punto de afirmar, aunque dentro del obiter dictum de una decisión, que las disposiciones de la Convención de la ONU de 2004, tienen efecto declarativo de la costumbre ${ }^{84}$.

Antes de entrar a revisar los escenarios bajo los cuales España podría pretender acceder a su alegado PCS, es importante aclarar que la solicitud que haga dicho Estado solo procederá sobre los bienes que de acuerdo con el procedimiento previsto por la Ley 1675 se excluyeron del PCS. Esto se da en aplicación de la interpretación jurisprudencial $^{85}$ de los criterios referidos en el artículo 3, que permite a partir del criterio de repetición, considerar a una parte de los bienes seriados o con valor de cambio o fiscal, como PCS y excluir de tal consideración a la otra parte, por decisión del Consejo Nacional de Patrimonio Cultural. Según esta Ley, los bienes excluidos estarán sujetos a

81 Supra nota 31, párrs. 54-56. La Corte Internacional de Justicia ha reconocido en varios casos la inaplicación de la costumbre a los Estados que se han opuesto a dicha práctica de manera persistente, no exitiendo por parte de ellos opinio iuris, o por el contrario, ha reconocido la aplicación de la costumbre para un Estado que no ha sido objetor persitente. Al respecto, ver por ejemplo: International Court of Justice, Fisheries case (United Kingdom vs. Norway), Judgment of 18 December, 1951, pág. 131. International Court of Justice, Asylum case (Colombia/Peru), Judgment of 20 November, 1950, pág. 277.

${ }^{82}$ Corte Constitucional de Colombia, sentencia C-137 de 1996, T-932 de 2010 y supra nota 39.

83 Ver supra nota 39.

${ }^{84}$ Si bien la Corte Constitucional en obiter dictum de la sentencia T-901 de 2013, establece que "Para este Tribunal, la práctica internacional y el efecto declarativo que representa la aprobación de la Convención conjugan los dos elementos constitutivos de la costumbre internacional (práctica y opinión concordante de los expertos, u opinio iuris)". Consideramos esta posición apresurada e irresponsable, pues, por un lado no hay verificación de práctica reiterada y menos de opinio iuris sobre todas las disposiciones de la Convención, y, segundo, porque la Corte no está midiendo el alcance de sus declaraciones en materia de vinculatoriedad para el Estado colombiano.

${ }^{85}$ Supra nota 21 , apartado 6.2. 
las normas sobre especies náufragas y salvamento ${ }^{86}$, las que disponen que dichos bienes se deben restituir a sus dueños ${ }^{87}$. Esto, precisamente, es lo que abre la posibilidad para que España acceda a una porción de los bienes que considera como de su PCS.

Teniendo en cuenta todo lo anterior, en este contexto se pueden presentar tres escenarios. El primero se materializa si España en virtud de las normas colombianas respecto de especies náufragas, solicita la restitución de los bienes que no entraron a hacer parte del PCS colombiano, alegando que son de su propiedad. Esta se podrá solicitar desde el momento en que se tiene certeza acerca de cuáles bienes están regidos por las normas de especies náufragas y salvamento; esto es, cuando el Consejo Nacional de Patrimonio Cultural expida una resolución determinando cuáles bienes son PCS y cuáles no. En este caso, una vez que las autoridades correspondientes decidan la solicitud a favor de España, restará a esta pagar las expensas y la gratificación al salvador que recuperó los bienes, y así obtenerlos efectivamente. La solicitud podrá hacerse igualmente durante el proceso judicial para la declaratoria de los bienes como mostrencos ${ }^{88}$, el que tiene como objeto la disposición por parte del Estado de tales bienes para comercializarlos o pagar con ellos al salvador ${ }^{89}$. En todo caso, la legislación permite que se realice la mencionada solicitud, hasta tanto los bienes no sean enajenados por el Estado ${ }^{90}$. En este primer escenario se acude a un mecanismo contemplado por la legislación interna y no a la figura de inmunidad de ejecución.

En el segundo escenario, y siguiendo con la lógica del procedimiento interno, en el proceso judicial que busca la declaratoria como mostrencos ${ }^{91}$ de los bienes que no fueron considerados PCS, el juez puede decretar medidas cautelares como el secuestro de los bienes o, una vez tomada la decisión de fondo, ordenar la entrega de los bienes al Estado. En este caso, España puede alegar inmunidad de ejecución frente a las medidas coercitivas que recaen sobre su alegada propiedad.

Finalmente, el tercer escenario se puede presentar si el salvador que recuperó los bienes inicia un proceso judicial alegando que el Estado colombiano incumplió el contrato que rige las actividades de recuperación, por ausencia de pago o porque este se llevó

86 Supra nota 13 , artículo 2.

87 Al respecto el artículo 699 del Código Civil colombiano, frente al hallazgo como forma de ocupación dispone que "No se presumen abandonadas por sus dueños las cosas que los navegantes arrojan al mar para alijar la nave”, siguiendo esta misma línea, en el artículo establece que "Las especies náufragas que se salvaren, serán restituidas por la autoridad a los interesados, mediante el pago de las expensas y la gratificación de salvamento".

${ }^{88}$ Conforme a los artículos 706, 710 y 712 del Código Civil Colombiano, si no se presentan interesados en especies naúfragas que fueron salvadas, estas se declararán como bienes mostrencos.

${ }^{89}$ El artículo 15 de la Ley 1675, faculta al Estado colombiano para pagar al salvador por las labores de recuperación, con hasta el $50 \%$ de los bienes encontrados que no constituyan PCS.

${ }^{90}$ De acuerdo con el artículo 709 del Código Civil colombiano frente a los bienes mostrencos, "Enajenada la cosa se mirará como irrevocablemente perdida para el dueño".

${ }^{91}$ Son aquellos bienes a cargo de la nación sin dueño aparente o conocido (Código Civil colombiano, artículo 706). 
a cabo desconociendo las condiciones pactadas ${ }^{92}$. En este caso, España también podrá acudir a la figura de inmunidad de ejecución, si en dicho proceso se decretan medidas cautelares $^{93}$ como las ya referidas, o medidas para darle cumplimiento a la decisión judicial como la orden de venta de los bienes para pagarle al salvador.

\section{CONCLUSIÓN}

De los tres escenarios se puede observar que, de prosperar los intereses de España y obtener los bienes, el Estado colombiano por lo menos implícitamente estaría reconociendo a España como propietario de los bienes. En el caso de la figura de inmunidad de ejecución, el reconocimiento es explícito, pues para hacer válida esta inmunidad, lo primero que debe demostrar España es la propiedad sobre los bienes objeto de la medida coercitiva. En este punto surgen cuestionamientos acerca de las posibilidades jurídicas y fácticas, de que los tribunales colombianos reconozcan que los bienes son PCS de España ${ }^{94}$ o que reconozcan que unos mismos bienes pueden constituir patrimonio cultural para dos o más Estados simultáneamente. En relación con las posibilidades jurídicas, la legislación colombiana parece ser coherente con la posibilidad de reconocer que el PCS puede ser compartido por varios Estados. Lo anterior, en virtud de contemplar la opción de que unos mismos bienes con idénticas características (los bienes seriados y de valor de cambio o fiscal) puedan tener una doble naturaleza y una triple dimensión. Por un lado, pueden ser bienes de dominio público al declararse como PCS y, por el otro, pueden ser bienes de dominio privado o, incluso, como se evidenció en el caso hipotético, bienes de dominio de un tercer Estado al excluirse del PCS colombiano.

92 El artículo 19 de la Ley 1675 de 2013, sobre PCS, dispone que "Las diferencias contractuales que surjan en desarrollo de los contratos previstos en la presente ley se someterán exclusivamente a la jurisdicción colombiana".

93 Frente a las medidas previas al fallo judicial, el artículo 18 de la Convención de las Naciones Unidas sobre inmunidades jurisdiccionales de los Estados y de sus bienes solo se pueden ordenar medidas coercitivas cuando el Estado las haya consentido expresamente o cuando el Estado haya asignado los bienes para satisfacción del litigio. Por tanto, en principio demostrando la titularidad de España sobre los bienes y sin necesidad de analizar si se trata de un acto de iure imperii o un acto de iure gestioni, procedería la inmunidad.

${ }^{94}$ En torno a este punto surgen debates interesantes, propios de situaciones en las que se vinculan a varios Estados que comparten parte de su historia, unos en su calidad de colonias y otros como Estados colonizadores. Ver supra nota 78. En este caso, tanto Colombia como España tienen argumentos para afirmar que los bienes en mención representan parte de su historia y su cultura nacional. Ejemplo de ello fue la intervención de Perú en el caso Las Mercedes, en el que dicha República alegó que el cargamento de tal embarcación pertenecía a su nación pues había sido elaborada en su territorio y por su población (Supra nota 44). 


\section{BIBLIOGRAFÍA}

\section{Libros y artículos}

Своок, J., "Contemporary Practice of the United States relating to International Law, State Jurisdiction and Immunities", en American Journal of International Law, vol. 106, núm. 1, enero de 2012.

Fox. H., The Law of State Immunity, Oxford University Press, Oxford, 2003.

International Law Commission, Yearbook of the International Law Commission 1980, United Nations, New York, 1981.

Jakubowski, A., "State Succession in Cultural Property", Oxford University Press, Nueva York, 2015.

Lauterpacht E. (Ed.) International Law Collected papers, 3. The Law of Peace parts II-VI, Cambridge University Press, Cambridge, 1977.

Pavoni, R., "Sovereign Immunity and the Enforcement if International Cultural Property Law", en Francioni, F. \& Gordley, J. (Edit.), Enforcing International Cultural Heritage Law, Oxford University Press, Oxford, 2013.

Sciso, E., "Italian Judges 'Point of View on Foreign States' Immunity", en Banderbilt Journal os Transnational Law, vol. 44, 2011.

Scovazzi, T., The Definition of Intangible Cultural Heritage, en Cultural Heritage, Cultural Rights, Cultural Diversity, New Developments in International Law, Martinus Nijhoff Publishers, Leiden, 2012.

ScovazzI, T., The Merits of the UNESCO Convention on the Protection of the Underwater Cultural Heritage, en Cultural Heritage, Cultural Rights, Cultural Diversity, New Developments in International Law, Martinus Nijhoff Publishers, Leiden, 2012.

SHAw. M., International Law, Cambridge University Press, Nueva York, 2003, p. 621.

Vigni, P., "Historic Shipwrecks and the Limits of the Flag State Exclusive Rights", en Silvia Borelli, Federico Lenzerini (Edit.), Cultural Heritage, Cultural Rights, Cultural Diversity. New Developments in International Law, Martinus Nijhoff Publishers, Leiden-Boston, 2012.

Decisiones judiciales

Corte Constitucional de Colombia, sentencias C-137 de 1996; T-932 de 2010; T-901 de 2013; C-264 de 2014.

Corte de Casación, Banco de la Nación vs. Crédito Varesino, SpA, Italia, Caso No. 5275.

Florida Middle District Court, Odyssey Marine Exploration, Inc. vs. The unidentified shipwrecked vessel, its apparel, tackle, appurtenances and cargo located within center point coordinates, In Rem, The Kingdom of Spain, et al.

International Court of Justice, Jurisdictional immunities of the state Germany vs. Italy: Greece intervening, Judgment of 3 February 2012.

International Court of Justice, Territorial and Maritime Dispute (Nicaragua vs. Colombia), Judgment of 19 November 2012.

Judicatura de Bélgica, Société pour la fabrication des cartouches vs. Col. M., Ministre de la Guerre de Bulgarie, 1889.

Sala de lo Contencioso Administrativo del Tribunal Superior de Justicia de Andalucía, con sede en Sevilla, sentencia de 26 de mayo de 2010.

Supreme Court of Lithuania, V. Stukonis vs. US embassy, 1998-01-05 LAT c.b. Nr. 3K-1/98. 
Supreme Court of the United States, Florida Department of State vs. Treasure Salvors, Inc., July 1, 1982.

Tribunal Constitucional de España, Sala Segunda. Sentencia 107/1992, de 1 de julio de 1992.

United States Court of Appeals for the Eleventh Circuit José Guevara vs. Republic of Peru, Ministerio del Interior, et al., November 1, 2006.

United States Court of Appeals for the Eleventh Circuit, Odyssey Marine Exploration, INC. vs. The Unidentified Shipwrecked vessel, its apparel, tackle, appurtenances and cargo located within center point coordinates, in rem., Kingdom of Spain, et al., 2011.

United States Court of Appeal for the Fourth Circuit, Sea Hunt Incorporated and Commonwealth of Virginia vs. The Unidentified Shipwrecked vessel or vessels their apparel, tackle, appurtenances, and cargo located within coordinates, in rem, kingdom of Spain, et al., July 21, 2000.

United States Court of Appeals for the Ninth Circuit, Maria V. Altmann vs. Republic of Austria, and the Austrian Gallery, an agency of the Republic of Austria, 2002.

Documentos en formato electrónico: última fecha de visita 29-08-2015.

Armada Española, informe de prensa de 31 de enero de 2013, disponible en http:// www.armada.mde.es/ArmadaPortal/page/Portal/ArmadaEspannola/ciencia_museo/ prefLang_es/01_informacion-museo-naval--02_prensa-museo-naval--01_noticias--2013-01--NT-014-Informe- naufragios_es?_selectedNodeID=1116007\&_pageAction =selectItem

Bernal, J. \& Contreras, C., "Unidad Coordinadora de Asistencia Técnica Legislativa, Ley 1147 de 2007”, en Congreso de la República de Colombia, Aquí Vive Colombia, Colombia, 2011, disponible en http://www.camara.gov.co/portal2011/comisiones/especiales/modernizacion/ unidad-asistencia-tecnica-legislativa

Gaukrodger, D., "Foreign State Immunity and Foreign Government Controlled Investors", OECD Working Papers on International Investment, 2010/02, OECD Publishing, disponible en http://dx.doi.org/10.1787/5km91p0ksqs7-enp. 13.

International Law Commission, "Draft Articles on Jurisdictional Immunities of States and their Property, with commentaries”, 1991, disponible en http://legal.un.org/ilc/texts/instruments/english/commentaries/4_1_1991.pdf

Ruíz, R., El régimen jurídico del patrimonio cultural subacuático, Ministerio de Defensa, http:// publicacionesoficiales.boe.es/

Toleikytè, N., "The Concept of State Immunity and the Main Challenges", disponible en http:// www.tf.vu.lt/dokumentai/Admin/Doktorant\%C5\%B3_konferencija/Toleikyte.pdf

Códigos, leyes, tratados

1926 International Convention for the Unification of Certain Rules Concerning the Immunity of Stateowned Ships and 1934 Additional Protocol

Código Civil Colombiano

Convención Europea sobre Inmunidad Estatal

Convención de las Naciones Unidas sobre el Derecho del Mar 1982

Convención de las Naciones Unidas sobre Inmunidades Jurisdiccionales de los Estados y de sus Bienes 2004

Convención para la Protección de los Bienes Culturales en caso de Conflicto Armado 1954

Convención sobre la Protección del Patrimonio Cultural Subacuático 2001

Convención sobre la Protección del Patrimonio Mundial, Cultural y Natural 
Convención sobre las Medidas que Deben Adoptarse para Prohibir e Impedir la Importación,

la Exportación y la Transferencia de Propiedad Ilícitas de Bienes Culturales 1970

DeCRETo 1698 de 2014

LEY 397 de 1997

LEY 1675 de 2013

LEY 16/1985, de 25 de junio, del Patrimonio Histórico Español

LEY 14/2014, de 24 de julio, de Navegación Marítima

LeY Orgánica 6/1985, de 1 de julio, del Poder Judicial

Resolución 2625 de 1970 de la A.G/NU 
